\title{
Physical activity prescription: a critical opportunity to address a modifiable risk factor for the prevention and management of chronic disease: a position statement by the Canadian Academy of Sport and Exercise Medicine
}

\author{
Jane S Thornton, ${ }^{1}$ Pierre Frémont, ${ }^{2}$ Karim Khan, ${ }^{3}$ Paul Poirier, ${ }^{4}$ Jonathon Fowles, ${ }^{5}$ \\ Greg D Wells, ${ }^{6}$ Renata J Frankovich ${ }^{7}$
}

${ }^{1}$ Western University, London, Ontario, Canada

${ }^{2}$ Dip Sport Med (CASEM), Laval University, Ville de Québec, Quebec, Canada ${ }^{3}$ University of British Columbia, Vancouver, British Columbia, Canada

${ }^{4}$ Institut Universitaire de Cardiologie et de Pneumologie de Québec and Faculty of Pharmacy, Laval University, Québec, Canada

${ }^{5}$ Acadia University, Wolfville,

Nova Scotia, Canada

${ }^{6}$ Hospital for Sick Children, University of Toronto, Toronto, Ontario, Canada

${ }^{7}$ Dip. Sport Med (CASEM), University of Ottawa, Ontario, Canada

\section{Correspondence to} Dr Jane S Thornton, Western University, 10 Harrison Crescent, London, Ontario, Canada N5Y 2V4; jane.s. thornton@gmail.com

Accepted 3 June 2016 Published Online First 22 June 2016

\section{CrossMark}

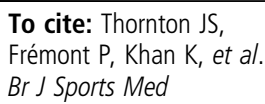

\begin{abstract}
Author note This position statement has been endorsed by the following nine sport medicine societies: Australasian College of Sports and Exercise Physicians (ACSEP), American Medical Society for Sports Medicine (AMSSM), British Association of Sports and Exercise Medicine (BASEM), European College of Sport \& Exercise Physicians (ECOSEP), Norsk forening for idrettsmedisin og fysisk aktivite (NIMF), South African Sports Medicine Association (SASMA), Schweizerische Gesellschaft für Sportmedizin/Swiss Society of Sports Medicine (SGSM/SSSM), Sport Doctors Australia (SDrA), Swedish Society of Exercise and Sports Medicine (SFAIM), and CASEM.
\end{abstract}

\section{ABSTRACT}

Non-communicable disease is a leading threat to global health. Physical inactivity is a large contributor to this problem; in fact, the WHO ranks it as the fourth leading risk factor for overall morbidity and mortality worldwide. In Canada, at least 4 of 5 adults do not meet the Canadian Physical Activity Guidelines of 150 min of moderate-to-vigorous physical activity per week. Physicians play an important role in the dissemination of physical activity $(\mathrm{PA})$ recommendations to a broad segment of the population, as over $80 \%$ of Canadians visit their doctors every year and prefer to get health information directly from them. Unfortunately, most physicians do not regularly assess or prescribe PA as part of routine care, and even when discussed, few provide specific recommendations. PA prescription has the potential to be an important therapeutic agent for all ages in primary, secondary and tertiary prevention of chronic disease. Sport and exercise medicine (SEM) physicians are particularly well suited for this role and should collaborate with their primary care colleagues for optimal patient care. The purpose of this Canadian Academy and Sport and Exercise Medicine position statement is to provide an evidence-based, best practices summary to better equip SEM and primary care physicians to prescribe PA and exercise, specifically for the prevention and management of non-communicable disease. This will be achieved by addressing common questions and perceived barriers in the field.

\section{INTRODUCTION}

Non-communicable disease is a leading threat to global health. Physical inactivity is a large contributor to this problem; in fact, the WHO ranks it as the fourth leading risk factor for overall morbidity and mortality worldwide. ${ }^{1}$ In Canada, at least four of five adults do not meet the Canadian Physical Activity Guidelines of $150 \mathrm{~min}$ of moderateto-vigorous physical activity (MVPA) per week. ${ }^{23}$
Prescription of physical activity (PA) is a key element of the multifaceted societal approach needed to address inactivity. ${ }^{4}$ Substantial evidence exists to support the benefits of exercise on at least 30 chronic diseases $^{6-10}$ as well as the costeffectiveness of exercise prescription in primary care, ${ }^{11}{ }^{12}$ even for cardiovascular (CV) disease alone. $^{13}$

Physicians play an important role in the dissemination of PA recommendations to a broad segment of the population. Over $80 \%$ of Canadians visit their doctors every year and prefer to get health information directly from their family physician. ${ }^{14}{ }^{15}$ Unfortunately, most physicians do not regularly assess or prescribe PA as a part of routine care, ${ }^{16-18}$ and even when discussed, few provide specific recommendations. ${ }^{19}$

PA prescription has the potential to be an important therapeutic agent for all ages in primary, secondary and tertiary prevention of chronic disease. Sport and exercise medicine (SEM) physicians are particularly well suited for this role and should collaborate with their primary care colleagues for optimal patient care. We must act now to correct the general lack of knowledge and training in our medical schools and residency programmes surrounding PA guidelines and prescription ${ }^{20-23}$ as well. The purpose of this Canadian Academy and

Definitions: Physical activity (PA), defined as 'any bodily movement produced by skeletal muscle', and exercise, which generally involves structured activity to improve a certain aspect of fitness, ${ }^{34}$ confer benefits with respect to chronic disease. PA is further categorised as light, moderate and vigorous (table 1). Sport is one form of delivery of PA and exercise, but is not the focus of this statement. 
Sport and Exercise Medicine (CASEM) position statement is therefore to provide an evidence-based, best practices summary to better equip SEM and primary care physicians to prescribe PA and exercise, specifically for the prevention and management of non-communicable disease. This will be achieved by addressing common questions and perceived barriers in the field.

\section{How effective is exercise prescription by primary care physicians?}

Exercise prescription is effective at increasing PA levels ${ }^{24-26}$ and can generate positive clinical outcomes such as reduced blood pressure and glycosylated haemoglobin, ${ }^{27-29}$ as well as important positive effects on mental health, ${ }^{30-32}$ reducing risk of depression $^{33}$ and improving cognitive function in older adults with dementia and Alzheimer's disease (AD). ${ }^{35}$ From an effectiveness standpoint, the number needed to treat (NNT) for one person to achieve the recommended adult PA guidelines of $150 \mathrm{~min}$ of MVPA per week, though brief physician counselling is $12 .{ }^{36}$ This is at least fourfold lower than the clinical effort to achieve a comparable health benefit of a smoker to quit smoking, which has an NNT of 50-120. ${ }^{26}$

Challenges exist, such as time constraints, complex comorbidities, perceived the lack of patient engagement and a lack of physician training or education on particulars of PA counselling. Some promising examples exist, however, such as Courneya et al's ${ }^{37}$ study, eliciting high rates of adherence to exercise prescription in patients with cancer. Exercise prescription is costeffective and can increase PA by $10 \%$ in relatively inactive patients, ${ }^{13} 373839$ a number which recent Canadian evaluations have estimated could save $\sim 2.1$ billion dollars per year in healthcare and other costs if adopted at the population level. ${ }^{40} 41$

Such counselling becomes even more effective in a range of situations in which: (1) there is an increased risk of chronic disease; (2) the encounter includes an individual assessment of needs, motivation, habits, preferences and barriers; (3) the message and goals are clear, simple and realistic; (4) valid behavioural change approaches are used and (5) proper follow-up, self-monitoring and social support are available. ${ }^{26}$ Medical practitioners' own PA habits influence their practice of PA historytaking and exercise prescription as well. ${ }^{18}$

\section{What are the key messages that should be given regarding the effective dose of exercise for the prevention and treatment of chronic disease?}

In a landmark British Medical Journal paper examining the head-to-head effects of medication versus PA/exercise in chronic disease, Naci and Ioannidis ${ }^{42}$ from Stanford University made a strong case for equivalent or superior effect of the health benefits of PA. In particular, PA interventions were more effective than drug treatment among patients with stroke and were as effective as medications for the prevention of diabetes and secondary treatment of $\mathrm{CV}$ disease. PA can be as effective as medications for the treatment of depression ${ }^{43}$ and has a potent effect on cognitive function in dementia in patients with $\mathrm{AD}$ and in patients with a diagnosis of AD or non-AD dementia. ${ }^{35}$

Several high-level systematic reviews have also identified risk reductions of $25-50 \%$ or more in most major chronic diseases for individuals who achieve $150 \mathrm{~min}$ of MVPA per week. ${ }^{9} 264445$ A systematic review of nine cohort studies with a mean follow-up of 9.8 years $^{46}$ and two recent prospective studies on large population cohorts (661 137 adults in the USA and Europe and 204542 adults in Australia, followed for 14 and 8 years, respectively) demonstrated clear dose-response effects of PA to overall mortality; ${ }^{47} 48$ each 10 min of MVPA accumulated per day led to a roughly $10 \%$ relative risk reduction in mortality, up to a $32-44 \%$ relative risk reduction at 150 min MVPA per week, depending on the amount of vigorous activity as a part of the MVPA. The dose-response effect appears to plateau at a $50-60 \%$ reduction at 3-5 times the guidelines (ie, $750 \mathrm{~min} /$ week), and there is no evidence of increased mortality at high levels of PA in generally healthy individuals.

Although this target of $150 \mathrm{~min}$ may seem out of reach for many who are sedentary, studies have shown significant benefits for those who complete even small amounts of PA. The biggest positive change in health risk is in going from inactive to somewhat active (ie, $75-90 \mathrm{~min} /$ week), resulting in a $15 \%$ reduction in mortality risk. ${ }^{26} 49$ Simply reducing sedentary behaviour confers short- and long-term health benefits, ${ }^{5051}$ as prolonged sedentary time is an independent predictor of adverse health outcomes in adults. ${ }^{52}$

Long-term efficacy

Adherence to PA (as with other lifestyle modifications) tends to decrease at 1 year, but can be sustained when activity is repeated, ${ }^{53}$ or combined with community supports. ${ }^{54}$ The Diabetes Prevention Program (DPP) observed the maintenance of adaptations and reduced diabetes incidence 10 years following intensive support for PA during the study, ${ }^{55}$ as was the case with a similar DPP in China ${ }^{56} 57$ which elicited reduced CV and all-cause mortality and incidence of diabetes at 20 years. The most cost-effective and practical option is brief PA counselling through primary care, which is proven effective at improving PA levels at 12 months following the intervention. ${ }^{26}$ Multiple sessions may extend this time period even further, ${ }^{53}$ as does exercise performed under supervision. ${ }^{58}$

\section{How can brief exercise assessment and prescription be integrated in primary care?}

There is evidence that a $2-4$ min intervention in primary care effectively promotes PA. ${ }^{59}$ Asking two simple questions regarding current PA (the exercise 'vital sign', 'EVS') at each visit can further inform effective counselling: (1) 'On average, how many days/week do you engage in moderate or greater physical activity (like a brisk walk)?' and (2) 'On those days, how many minutes do you engage in activity at this level? ${ }^{\circ 0}$ Regular EVS monitoring can change physician behaviour and improve patients' risk of disease. ${ }^{61}$ If the physician has more time than that of a typical family practice appointment, motivational interviewing is an effective method to raise the possibility of any behavioural intervention. ${ }^{1062}$

A written prescription (which comprises exercise and lifestyle goals) is a crucial element to signal that PA and exercise can be therapeutic. ${ }^{63}$ For patients with stable conditions, general practitioners can provide customised exercise prescription. Incorporating discussions surrounding the use of advanced technology ${ }^{64}$ is discussed later in this article. Healthy patients are encouraged to join community-based programmes and may exercise independently without supervision. PA guidelines should also be prominent in the waiting room.

Physicians who do not have training in exercise prescription may refer to skilled allied health professionals and to appropriate community-based resources. Follow-up is crucial, however, to signal the clinician's conviction, determine the patient's progress, solve problems, help identify social support, fine-tune the dose and reset goals. 
Table 1 Descriptors of physical activity

\begin{tabular}{|c|c|c|c|}
\hline Intensity & Objective measures & What patient feels* & Typical examples \\
\hline Sedentary & $\begin{array}{l}<1.6 \mathrm{METs} \\
<40 \% \mathrm{HRmax} \\
<20 \% \mathrm{VO}_{2} \max \end{array}$ & - At rest with limited added movement & $\begin{array}{l}\text { - Sitting and reading } \\
\text { Watching TV } \\
\text { - Driving a car }\end{array}$ \\
\hline Light & $\begin{array}{l}1.6-3.0 \text { METs } \\
40-55 \% \mathrm{HRmax} \\
20-40 \% \mathrm{VO}_{2} \max \end{array}$ & $\begin{array}{l}\text { Active } \\
\text { No noticeable change in breathing/ } \\
\text { sweating } \\
\text { Can be sustained for } 1 \text { hour or more }\end{array}$ & $\begin{array}{l}\text { Slow walking (eg, around the house) } \\
\text { Light work while standing (eg, cooking, washing dishes) } \\
\text { Playing an instrument }\end{array}$ \\
\hline Moderate & $\begin{array}{l}\text { 3-6 METs } \\
55-70 \% \mathrm{HRmax} \\
40-60 \% \mathrm{VO}_{2} \max \end{array}$ & $\begin{array}{l}\text { Increased breathing and sweating, but } \\
\text { - Still able to maintain a conversation } \\
\text { - Can sustain activity for 30-60 min }\end{array}$ & $\begin{array}{l}\text { Brisk walk } \\
\text { Low movement racquet games (eg, doubles tennis, recreational badminton) } \\
\text { Water aerobics } \\
\text { Resistance exercise } \\
\text { - Mowing the lawn }\end{array}$ \\
\hline Vigorous & $\begin{array}{l}\text { 6-9 METs } \\
70-90 \% \mathrm{HRmax} \\
60-85 \% \mathrm{VO}_{2} \max \end{array}$ & $\begin{array}{l}\text { Feeling 'out of breath' } \\
\text { Increased sweating } \\
\text { Can be difficult to maintain a } \\
\text { conversation } \\
\text { Can sustain activity for up to } 30 \text { min }\end{array}$ & $\begin{array}{l}\text { Jogging } \\
\text { Hiking } \\
\text { Swimming with effort } \\
\text { Higher movement racquet games (eg, singles tennis and squash) } \\
\text { Field/ball games (eg, soccer and basketball) } \\
\text { Cross-country skiing } \\
\text { Shovelling }\end{array}$ \\
\hline High & $\begin{array}{l}\geq 9 \mathrm{METs} \\
\geq 90 \% \mathrm{HRmax} \\
\geq 85 \% \mathrm{VO}_{2} \max \end{array}$ & $\begin{array}{l}\text { Feels like giving } 100 \% \\
\text { All-out bursts of between } 1 \text { and } 2 \text { min } \\
\text { Intensity cannot be sustained for more } \\
\text { than } 10 \text { min }\end{array}$ & $\begin{array}{l}\text { Training/competing in most competitive sports } \\
\text { Racing or any all-out activity (eg, running, rowing, swimming, skiing and } \\
\text { high-intensity intervals) }\end{array}$ \\
\hline
\end{tabular}

Box 1 Key messages for patients during the discussion of the health benefits of physical activity

- Exercise is more effective than medication for the treatment of stroke and as effective for the secondary prevention of coronary heart disease and diabetes.

- A 150 min of moderate-to-vigorous physical activity (MVPA) accumulated per week can reduce the risk of most major chronic diseases by $25-50 \%$.

- A $15 \mathrm{~min}$ of MVPA per day (or $75 \mathrm{~min} /$ week) is associated with a $\sim 15 \%$ relative mortality risk reduction, and benefits increase with the dose.

\section{What terminology and examples can be used to describe PA intensity to patients?}

Effective counselling requires physicians to clearly explain to their patients what is meant by terms like MVPA and advise on ways to limit sedentary behaviour. Different PA intensities are described in table 1.

Activities that correspond to any given level of intensity will change with the degree of an individual's CV fitness; for example, once a previously untrained patient has been regularly active at a moderate intensity through walking for several weeks, what counts as brisk at first may become a lighter intensity exercise (boxes 1-3).

\section{What are the safety considerations prior to initiation of an exercise prescription?}

For healthy patients, a gradual progression towards regular MVPA is safe and recommended. Participation in light to moderate exercise confers very little risk and can be 'selfadministered', akin to an over-the-counter medication. ${ }^{66}$ For

\section{Box 2 Practical steps for immediate exercise prescription}

Ask about physical activity (PA) at every consultation.

- A written prescription building towards accumulating $150 \mathrm{~min} /$ week is crucial-it takes just $30 \mathrm{~s}$ to do this.

- Encourage the patient to measure (eg, pedometer and smart phone) and record their PA (paper and mobile app).

- Refer on as appropriate-consider appropriate physicians, physiotherapists, clinical exercise physiologists, kinesiologists and certified fitness instructors.

- Follow-up with the patient to chart progress, set goals, solve problems, and identify and use social support.

those with stable asymptomatic CV, metabolic or renal disease, medical clearance is not needed for patients already active, but recommended for those who are inactive. Although these two categories represent the majority of patients in a typical primary care practice, physicians are often concerned with CV risk in patients with more serious conditions.

Self-screening instruments such as the Physical Activity Readiness Questionnaire (PAR-Q +$)^{67}$ or the American College of Sport Medicine (ACSM) health screening guidelines ${ }^{68}$ direct people to a physician for further evaluation when current symptoms suggestive of $\mathrm{CV}$, metabolic or renal disease or complex comorbidities are present. In these cases, the physician should evaluate the clinical condition of the patient through a history and physical examination that will focus on contraindications to exercise. Patients with unstable angina, uncharacterised arrhythmias or decompensated heart failure should not perform vigorous exercise before their conditions stabilise. Physical examination should focus on significant clinical signs, such as a heart murmur, pulmonary overload or severe hypertension 
(resting blood pressure $>200 / 110 \mathrm{~mm} \mathrm{Hg}$ ), which can indicate potential heightened risk. ${ }^{36} 69$

The estimated prevalence of complications requiring hospitalisation (including serious arrhythmias), acute myocardial infarction or sudden cardiac death (SCD) during or immediately after a stress test are $\leq 0.2 \%, 0.04 \%$ and $0.01 \%$, respectively. ${ }^{70}$ Vigorous intensity exercise acutely, albeit transiently, increases CV events. ${ }^{71}$ In a prospective study of sport-related SCD in the general population, however, the incidence of SCD was estimated to 4.6 per million population per year or $0.00046 \%{ }^{72}$ Based on these numbers, it can be concluded that the gradual progression towards MVPA by a sedentary patient with stable chronic conditions and a normal history and physical is associated with such a low rate of $\mathrm{CV}$ events that further formal $\mathrm{CV}$ testing is not indicated.

\section{High-intensity interval training}

Recently, high-intensity interval training (HIIT) has been promoted based on several systematic reviews, ${ }^{73}$ showing greater benefits on $\mathrm{CV}$ fitness compared to lower intensity continuous training. HIIT involves alternate bursts of short, intense PA interspersed with recovery periods and appears to be safe for rehabilitation of patients with coronary artery disease and heart failure, ${ }^{75}$ although there are conflicting opinions in the literature as to its effectiveness and safety for population-level exercise. ${ }^{76}$ For patients considered at higher CV risk, therefore, stress testing is advised.

\section{Is it safe to prescribe exercise if my patient has osteoarthritis or other comorbidities?}

Several recent systematic reviews demonstrate that aerobic and resistance exercise will not result in increased pain or disability in patients with osteoarthritis. ${ }^{78-81}$ In fact, both types of training generally reduce pain and increase function; further supporting the expert consensus recommendations that PA should be a part of management. ${ }^{82-84}$

Regarding individualised adaptation of exercise prescription to specific chronic disease, the reader is referred to the free online textbook provided by the Swedish Institute of Public Health $^{10}$ and two recent review articles. ${ }^{9}{ }^{85}$ In general, as mentioned earlier, if the patient has one or two stable chronic diseases and is otherwise healthy, PA can be self-administered, with a gradual progression towards the adult PA guidelines.

\section{Which tools can help patients adopt active behaviours?}

While the ubiquity of mobile phones and wearable technology may present a simpler method for clinicians to assess and promote active behaviours in primary care, the evidence in this area is still underdeveloped. ${ }^{86}$ Meta-analysis of pedometer use demonstrates average increases of over 2000 steps in participants' steps per day. ${ }^{87}$ Step count targets for adults, using a guide of 100 steps/min as 'moderate intensity', are in the range of roughly 7100-11 000 steps per day, with $<5000$ steps a day leading to adverse health outcomes; ${ }^{88}$ therefore, this can represent a significant improvement.

Data extraction may be time-consuming for patient and clinician, however, which may explain low levels of user adoption, despite the benefits of many PA monitors. Individuals using wearable technology to improve their health exhibit the most consistent usage when tracking is simple and automatic. ${ }^{89}$ Other technologies that may improve adherence to PA are text messaging ${ }^{90}$ and 'exergames'. ${ }^{91} 92$ Advances in the field of mobile apps for PA monitoring for health will inevitably continue and become more user-friendly for patients and doctors. Physicians

\section{Box 3 Key messages regarding cardiovascular safety}

- For generally healthy individuals, moderate exercise is safe. If inactive, begin with lower intensity and progress in duration and intensity over time.

- Progression towards recommended volumes of moderate-tovigorous physical activity (MVPA) can be prescribed to patients with chronic disease. If inactive initially, a normal clinical evaluation is recommended. If already active, medical clearance is recommended before engaging in vigorous activities.

- Initiation of high-intensity physical activity, such as high-intensity interval training, should be preceded by establishing a 'base fitness level' over several weeks through regular MVPA. ${ }^{77}$

are encouraged to be flexible and creative in their adoption of new devices to this end.

\section{How can exercise professionals contribute to the implementation of an active lifestyle?}

The role of exercise professionals through physician referral of patients must be carefully considered, so that an additional burden of treatment such as added costs for the patient or ease of access limitations do not raise barriers to integration of daily PA. Avoiding these and other potential obstacles is of particular concern for lower socioeconomic groups; medical professionals must be aware that those most at risk of disease are often the least able to afford the cure. In most cases, physicians should feel enabled to prescribe PA without referral, assuming appropriate safety considerations are made and gradual introduction of PA for the sedentary patient is advised. Nevertheless, physicians are encouraged to identify potential partners within their communities (eg, local recreation centres, sports programmes and walking/running groups) to build effective networks for patient referral and/or direction when desired.

Exercise professionals and other PA facilitators can be important members of an integrated approach to design and delivery of interventions, although experts point to the lack of evidence and sustainability for exercise referral schemes. ${ }^{93-96}$ Referral to a qualified exercise professional is most indicated for patients with conditions classified as high risk of morbidity and mortality associated with the lack of PA (CV disease and type 2 diabetes), as well as special populations that would benefit from PA but have difficulty engaging due to low motivation or safety concerns (patients with cancer, epilepsy or pulmonary disease). In many patients with chronic disease such as diabetes, exercise programmes are most effective when supervised. ${ }^{97}$ Therefore, the role of the exercise professional is to ensure safety and adaptation to ability level of the patient and to ensure accountability for maximal treatment efficacy.

It is important to remember that patient empowerment is essential and the physician must communicate his or her belief that the patient is capable of change. Considerations should be made for the education and awareness-building for the patient, family and support network as a part of the total programme.

\section{CONCLUSION}

Primary care providers, and particularly SEM physicians, have an important opportunity to make PA an integral component of the prevention and treatment of chronic disease. It is the 
position of the CASEM that all SEM and primary care physicians should include PA assessment and prescription as part of routine healthcare for patients, and this should be a priority for training and education at every level of medicine.

Recommendations from physicians influence patient engagement and improve the likelihood of adoption. CASEM further recommends that clinicians lead by example and integrate PA into their own lives, for their own health and well-being, and to provide further credibility and empathy for the challenges patients face.

Physical inactivity is and will remain one of the gravest threats to public health for this and future generations of Canadians unless a catalyst for change can be found. With a simple prescription for PA, front-line physicians have one more tool to bring about real change in the lives of Canadians. With the evidence summarised in this review, the message is clear that PA prescription works and costs less than relying on the alternatives alone. The time to act is now.

Correction notice This paper has been amended since it was published Online First. The author note has been moved from the end matter to the first page.

Twitter Follow Jane Thornton at @janesthornton

Acknowledgements The authors thank Dr Amir Pakravan, Dr Jorge A Ruivo, Dr Nikos Malliarpoulos and Dr Hamish Osbourne for their thorough review of this manuscript prior to submission.

Contributors JT takes overall responsibility for the original concept and content. $\mathrm{PF}, \mathrm{KK}$ and RF contributed to the original structure. JT, PF, KK, PP, GDW and JF contributed directly to the content. AP, JAR, NM and HO provided expert review of the article prior to submission.

Competing interests None declared.

Provenance and peer review Not commissioned; externally peer reviewed.

\section{REFERENCES}

1 World Health Organization. WHO Global Recommendations on Physical Activity for Health. Geneva: World Health Organization, 2010. http://apps.who.int/iris/bitstream/ 10665/44399/1/9789241599979_eng.pdf (accessed 22 Mar 2016).

2 Canadian Society for Exercise Physiology. Canadian Physical Activity Guidelines. Ottawa, Canada: Canadian Society for Exercise Physiology, 2011. http://www.csep. ca/guidelines (accessed 22 Mar 2016).

3 Statistics Canada. 'Directly measured physical activity of Canadian adults, 2012 and 2013'. Health Fact Sheet. Statistics Canada Catalogue no. 82-625-X. http://www. statcan.gc.ca/pub/82-625-x/2015001/article/14135-eng.htm\# (accessed 22 Mar 2016).

4 MacAuley D, Bauman A, Frémont P. Not a miraculous cure-just good medicine. BMJ 2015:350:h1416

5 Trost SG, Blair SN, Khan KM. Physical inactivity remains the greatest public health problem of the 21st century: evidence, improved methods and solutions using the ' 7 investments that work' as a framework. Br J Sports Med 2014:48:169-70.

6 Holmes MD, Chen WY, Feskanich D, et al. Physical activity and survival after breast cancer diagnosis. JAMA 2005:293:2479-86.

7 Slattery ML, Potter JD. Physical activity and colon cancer: confounding or interaction? Med Sci Sports Exerc 2002;34:913-19.

8 Wei M, Gibbons LW, Mitchell TL, et al. The association between cardiorespiratory fitness and impaired fasting glucose and type 2 diabetes mellitus in men. Ann Intern Med 1999:130:89-96.

9 Pedersen BK, Saltin B. Exercise as medicine-evidence for prescribing exercise as therapy in 26 different chronic diseases. Scand J Med Sci Sports 2015;25(Suppl 3): 1-72

10 Professional Associations for Physical Activity-Swedish National Institute of Public Health. Physical Activity in the Prevention and Treatment of Chronic Disease. 2010. http://www.fyss.se/wp-content/uploads/2011/02/fyss 2010 english.pdf (accessed 22 Mar 2016)

11 Garrett S, Elley CR, Rose SB, et al. Are physical activity interventions in primary care and the community cost-effective? A systematic review of the evidence. $\mathrm{Br} J \mathrm{Gen}$ Pract 2011;61:e125-33.

12 Anokye NK, Lord J, Fox-Rushby J. Is brief advice in primary care a cost-effective way to promote physical activity? Br J Sports Med 2014;48:202-6.

13 Elley R, Kerse N, Arroll B, et al. Cost-effectiveness of physical activity counselling in general practice. N Z Med J 2004;117:U1216.
14 Blair SN, Wei M, Lee CD. Cardiorespiratory fitness determined by exercise heart rate as a predictor of mortality in the Aerobics Center Longitudinal Study. J Sports Sci 1998; 16(Suppl):S47-55.

15 Hesse $B$, Morise A, Pothier CE, et al. Can we reliably predict long-term mortality after exercise testing? An external validation. Am Heart J 2005;150:307-14.

16 Petrella RJ, Lattanzio CN, Overend TJ. Physical activity counseling and prescription among Canadian primary care physicians. Arch Intern Med 2007:167:1774-81.

17 Croteau K, Schofield G, McLean G. Physical activity advice in the primary care setting: results of a population study in New Zealand. Aust N Z J Public Health 2006:30: 262-7.

18 Lobelo F, Duperly J, Frank E. Physical activity habits of doctors and medical students influence their counselling practices. Br J Sports Med 2009;43:89-92.

19 Short CE, Hayman M, Rebar AL, et al. Physical activity recommendations from general practitioners in Australia. Results from a national survey. Aust N Z J Public Health 2016;40:83-90

20 Dunlop M, Murray AD. Major limitations in knowledge of physical activity guidelines among UK medical students revealed: implications for the undergraduate medical curriculum. Br J Sports Med 2013;47:718-20.

21 Savill B, Murray A, Weiler R. Is general practice engaged with physical activity promotion? Br J Gen Pract 2015:65:484-5.

22 Burdick L, Mielke Gl, Parra DC, et al. Physicians', nurses' and community health workers' knowledge about physical activity in Brazil: a cross-sectional study. Prev Med Rep 2015:10:467-72.

23 Sawyer A, Smith L, Schrempft S, et al. Primary caregiver knowledge of paediatric physical activity recommendations in the United Kingdom and its association with caregiver behaviour: an observational study. BMC Public Health 2014;4:795.

24 Grandes G, Sanchez A, Sanchez-Pinilla RO, et al. Effectiveness of physical activity advice and prescription by physicians in routine primary care: a cluster randomized trial. Arch Intern Med 2009;169:694-701.

25 Vuori IM, Lavie CJ, Blair SN. Physical activity promotion in the health care system. Mayo Clin Proc 2013:88:1446-61.

26 Stevens Z, Barlow C, Kendrick D, et al. Effectiveness of general practice-based physical activity promotion for older adults: systematic review. Prim Health Care Res Dev 2014;15:190-201.

27 Pinto BM, Goldstein MG, Ashba J, et al. Randomized controlled trial of physical activity counseling for older primary care patients. Am J Prev Med 2005;29:247-55

28 Huang N, Pietsch J, Naccarella L, et al. The Victorian Active Script Programme: promising signs for general practitioners, population health, and the promotion of physical activity. Br J Sports Med 2004;38:19-25.

29 Petrella RJ, Lattanzio CN. Does counseling help patients get active? Systematic review of the literature. Can Fam Physician 2002;48:72-80

30 Beaulac J, Carlson A, Boyd RJ. Counseling on physical activity to promote mental health: Practical guidelines for family physicians. Can Fam Physician 2011:57:399-401.

31 Martinsen EW. Physical activity in the prevention and treatment of anxiety and depression. Nord J Psychiatry 2008;62(Suppl 47):25-9.

32 Ströhle A. Physical activity, exercise, depression and anxiety disorders. J Neural Transm (Vienna) 2009:116:777-84.

33 Mammen G, Faulkner G. Physical activity and the prevention of depression: a systematic review of prospective studies. Am J Prev Med 2013;45:649-57.

34 Caspersen CJ, Powell KE, Christenson GM. Physical activity, exercise, and physical fitness: definitions and distinctions for health-related research. Public Health Rep 1985:100:126-31.

35 Groot C, Hooghiemstra AM, Raijmakers PG, et al. The effect of physical activity on cognitive function in patients with dementia: a meta-analysis of randomized control trials. Ageing Res Rev 2016;25:13-23.

36 Orrow G, Kinmonth AL, Sanderson S, et al. Effectiveness of physical activity promotion based in primary care: systematic review and meta-analysis of randomised controlled trials. BMJ 2012;344:e1389.

37 Courneya KS, McKenzie DC, Reid RD, et al. Barriers to supervised exercise training in a randomized controlled trial of breast cancer patients receiving chemotherapy. Ann Behav Med 2008:35:116-22.

38 Elley CR, Kerse N, Arroll B, et al. Effectiveness of counselling patients on physical activity in general practice: cluster randomised controlled trial. BMJ 2003;326:793

39 Dalziel K, Segal L, Elley CR. Cost utility analysis of physical activity counselling in general practice. Aust N Z J Public Health 2006;30:57-63.

40 Kruger J, Brennan A, Strong $M$, et al. The cost-effectiveness of a theory-based online health behaviour intervention for new university students: an economic evaluation. BMC Public Health 2014;14:1011.

41 Bounajm F, Dinh T, Theriault L. Moving ahead: the economic impact of reducing physical inactivity and sedentary behaviour. The Conference Board of Canada, 24 October 2014. http://www.conferenceboard.ca/e-library/abstract.aspx?did=6436 (accessed 22 Mar 2016).

42 Naci $H$, loannidis JPA. Comparative effectiveness of exercise and drug interventions on mortality outcomes: metaepidemiological study. BMJ 2013;347:f5577. 
43 Babyak M, Blumenthal JA, Herman S, et al. Exercise treatment for major depression: maintenance of therapeutic benefit at 10 months. Psychosom Med 2000;62:633-8.

44 Warburton $D E$, Charlesworth $\mathrm{S}$, Ivey $\mathrm{A}$, et al. A systematic review of the evidence for Canada's Physical Activity Guidelines for Adults. Int I Behav Nutr Phys Act 2010;7:39.

45 Tremblay MS, Warbuton DE, Janssen I, et al. New Canadian physical activity guidelines. Appl Physiol Nutr Metab 2011;36:36-46.

46 Hupin D, Roche F, Gremeaux V, et al. Even a low-dose of moderate-to-vigorous physical activity reduces mortality by $22 \%$ in adults aged $\geq 60$ years: a systematic review and meta-analysis. Br J Sports Med 2015;49:1262-7.

47 Arem H, Moore SC, Patel A, et al. Leisure time physical activity and mortality: a detailed pooled analysis of the dose-response relationship. JAMA Intern Med 2015;175:959-67.

48 Gebel K, Ding D, Chey T, et al. Effect of moderate to vigorous physical activity on all-cause mortality in middle-aged and older Australians. JAMA Intern Med 2015:175:970-7

49 Wen CP, Wai JP, Tsai MK, et al. Minimum amount of physical activity for reduced mortality and extended life expectancy: a prospective cohort study. Lancet 2011;378:1244-53.

50 Wilmot EG, Edwardson CL, Achana FA, et al. Sedentary time in adults and the association with diabetes, cardiovascular disease and death: systematic review and meta-analysis. Diabetologia 2012;55:2895-905.

51 de Rezende LF, Rodrigues Lopes M, Rey-López JP, et al. Sedentary behavior and health outcomes: an overview of systematic reviews. PLOS ONE 2014;9:e105620.

52 Biswas A, Oh P, Faulkner GE, et al. Sedentary time and its association with risk for disease incidence, mortality, and hospitalization in adults: a systematic review and meta-analysis. Ann Intern Med 2015;162:123-32.

53 Gagliardi AR, Abdallah F, Faulkner G, et al. Factors contributing to the effectiveness of physical activity counselling in primary care: a realist systematic review. Patient Educ Couns 2015;98:412-19.

54 Kahn EB, Ramsey LT, Brownson RC, et al. The effectiveness of interventions to increase physical activity. A systematic review. Am J Prev Med 2002;22(4 Suppl):73-107.

55 Knowler WC, Barrett-Connor E, Fowler SE, et al., Diabetes Prevention Program Research Group. Reduction in the incidence of type 2 diabetes with lifestyle intervention or metformin. N Engl J Med 2002:346:393-403.

56 Li G, Zhang P, Wang J, et al. Cardiovascular mortality, all-cause mortality, and diabetes incidence after lifestyle intervention for people with impaired glucose tolerance in the Da Qing Diabetes Prevention Study: a 23-year follow-up study. Lancet Diabetes Endocrinol 2014; 2:474-80.

57 Pan XR, Li GW, Hu YH, et al. Effects of diet and exercise in preventing NIDDM in people with impaired glucose tolerance. The Da Qing IGT and Diabetes Study. Diabetes Care 1997:20:537-44.

58 Balducci S, Sacchetti M, Haxhi J, et al. Physical exercise as therapy for type 2 diabetes mellitus. Diabetes Metab Res Rev 2014;30(Suppl 1):13-23.

59 National Institute for Health and Care Excellence (NICE). Physical activity: brief advice for adults in primary care NICE guidelines [PH44] Published date: May 2013. https://www.nice.org.uk/guidance/ph44 (accessed 22 Mar 2016).

60 Sallis R. Developing healthcare systems to support exercise: exercise as the fifth vital sign. Br J Sports Med 2011;45:473-4.

61 Grant RW, Schmittdiel JA, Neugebauer RS, et al. Exercise as a vital sign: a quasi-experimental analysis of a health system intervention to collect patient-reported exercise levels. J Gen Intern Med 2014;29:341-8.

62 Morton K, Beauchamp M, Prothero A, et al. The effectiveness of motivational interviewing for health behaviour change in primary care settings: a systematic review. Health Psychol Rev 2015;9:205-23.

63 Handcock P, Jenkins C. The Green Prescription: a field of dreams? N Z Med J 2003:116:U713

64 Marcus BH, Ciccolo JT, Sciamanna CN. Using electronic/computer interventions to promote physical activity. Br J Sports Med 2009; 43:102-5.

65 Norton K, Norton L, Sadgrove D. Position statement on physical activity and exercise intensity terminology. J Sci Med Sport 2010;13:496-502.

66 Bredin SS, Gledhill N, Jamnik VK, et al. PAR-Q+ and ePARmed-X+: new risk stratification and physical activity clearance strategy for physicians and patients alike. Can Fam Physician 2013; 59:273-7.

67 Warburton DE, Jamnik VK, Bredin SSD, et al. The 2015 Physical Activity Readiness Questionnaire for Everyone (PAR-Q+) and electronic Physical Activity Readiness Medical Examination (ePARmed-X+). Health Fitness J 2015;8:53-6.

68 Riebe D, Franklin BA, Thompson PD, et al. Updating ACSM's Recommendations for Exercise Preparticipation Health Screening. Med Sci Sports Exerc 2015; 47: 2473-9.

69 Fletcher GF, Ades PA, Kligfield P et al., American Heart Association Exercise, Cardiac Rehabilitation, and Prevention Committee of the Council on Clinical Cardiology, Council on Nutrition, Physical Activity and Metabolism, Council on Cardiovascular and Stroke Nursing, and Council on Epidemiology and Prevention. Exercise standards for testing and training: a scientific statement from the American Heart Association. Circulation 2013;128:873-934.
70 Myers J, Forman DE, Balady GJ, et al. Supervision of exercise testing by nonphysicians: a scientific statement from the American Heart Association. Circulation 2014;130:1014-27

71 Eijsvogels TM, Molossi S, Lee DC, et al. Exercise at the extremes: the amount of exercise to reduce cardiovascular events. J Am Coll Cardiol 2016;67:316-29.

72 Marijon E, Tafflet M, Celermajer DS, et al. Sports-related sudden death in the general population. Circulation 2011;124:672-81.

73 Milanović Z, Sporiš G, et al. Effectiveness of high-intensity interval training (HIT) and continuous endurance training for $\mathrm{VO}_{2 \max }$ improvements: a systematic review and meta-analysis of controlled trials. Sports Med 2015:45:1469-81.

74 Ramos JS, Dalleck LC, Tjonna AE, et al. The impact of high-intensity interval training versus moderate-intensity continuous training on vascular function: a systematic review and meta-analysis. Sports Med 2015:45:679-92.

75 Rognmo $\varnothing$, Moholdt T, Bakken $\mathrm{H}$, et al. Cardiovascular risk of high- versus moderate-intensity aerobic exercise in coronary heart disease patients. Circulation 2012;126:1436-40.

76 Biddle SJ, Batterham AM. High-intensity interval exercise training for public health: a big HIT or shall we HIT it on the head? Int J Behav Nutr Phys Act 2015;12:95.

77 ACSM's Consumer Information Committee. ACSM information on high-intensity interval training. 2014. https://www.acsm.org/docs/brochures/ high-intensity-interval-training.pdf (accessed 17 Feb 2016).

78 Brosseau L, Wells GA, Pugh AG, et al. Ottawa panel evidence-based clinical practice guidelines for therapeutic exercise in the management of hip osteoarthritis. Clin Rehabil. Published Online First: 2015 (accessed 22 Mar 2016).

79 Juhl C, Christensen R, Roos EM, et al. Impact of exercise type and dose on pain and disability in knee osteoarthritis: a systematic review and meta-regression analysis of randomized controlled trials. Arthritis Rheumatol 2014;66:622-36.

80 Quicke JG, Foster NE, Thomas MJ, et al. Is long-term physical activity safe for older adults with knee pain? A systematic review. Osteoarthritis Cartilage 2015:23:1445-56.

81 Tanaka R, Ozawa J, Kito N, et al. Efficacy of strengthening or aerobic exercise on pain relief in people with knee osteoarthritis: a systematic review and meta-analysis of randomized controlled trials. Clin Rehabil 2013; 27:1059-71.

82 National Institute for Health and Care Excellence (NICE). Osteoarthritis Care and Management in Adults [CG177]. Published date: February 2014. https://www.nice. org.uk/guidance/cg177 (accessed 22 Mar 2016)

83 Fernandes L, Hagen KB, Bijlsma JWJ, et al., European League Against Rheumatism (EULAR). EULAR recommendations for the non-pharmacological core management of hip and knee osteoarthritis. Ann Rheumatic Dis 2013:72:1125-35.

84 McAlindon TE, Bannuru RR, Sullivan MC, et al. OARSI guidelines for the non-surgical management of knee osteoarthritis. Osteoarthritis Cartilage 2014;22:363-88.

85 Hoffmann TC, Maher CG, Briffa T, et al. Prescribing exercise interventions for patients with chronic conditions. CMAJ 2016;188:510-18.

86 Strath SJ, Kaminsky LA, Ainsworth BE, et al. Guide to the assessment of physical activity: clinical and research applications: a scientific statement from the American Heart Association. Circulation 2013;128:2259-79.

87 Bravata DM, Smith-Spangler C, Sundaram V, et al. Using pedometers to increase physical activity and improve health: a systematic review. JAMA 2007;298:2296-304.

88 Tudor-Locke C, Craig CL, Brown WJ, et al. How many steps/day are enough? For adults. Int J Behav Nutr Phys Act 2011:8:79.

89 Choe EK, Lee NB, Lee B, et al. Understanding quantified-selfers' practices in collecting and exploring personal data. Proceedings of the 32nd Annual ACM Conference on Human Factors in Computing Systems; ACM, 2014:1143-52.

90 Chow CK, Redfern J, Hillis GS, et al. Effect of lifestyle-focused text messaging on risk factor modification in patients with coronary heart disease: a Randomized Clinical Trial. JAMA 2015;314:1255-63.

91 Chen FX, King AC, Hekler EB. Healthifying exergames: improving health outcomes through intentional priming. Proceedings of the 32nd Annual ACM Conference on Human Factors in Computing Systems; ACM, 2014:1855-64.

92 Lwin MO, Malik $\mathrm{S}$. The efficacy of exergames-incorporated physical education lessons in influencing drivers of physical activity: a comparison of children and pre-adolescents. Psychol Sport Exerc 2012;13:756-60.

93 National Institute for Health and Care Excellence (NICE). Physical activity: exercise referral schemes [PH54]. Published date: September 2014. https://www.nice.org.uk/ guidance/ph54 (accessed 22 Mar 2016)

94 Pavey TG, Anokey N, Taylor AH, et al. The clinical effectiveness of exercise referral schemes: a systematic review and meta-analyses. BMJ 2011;343:d6462.

95 Williams NH, Hendry M, France $B$, et al. Effectiveness of exercise-referral schemes to promote physical activity in adults: systematic review. Br J Gen Pract 2007;57:979-86.

96 Pakravan A, Jones A. Exercise Referral Schemes in Primary Care: Where does Sport and Exercise Medicine stand? [BJSM blog] 16 March 2014. http://blogs.bmj.com/ bjsm/2014/03/16/exercise-referral-schemes-in-primary-care-where-does-sport-andexercise-medicine-stand/ (accessed 17 Feb 2016).

97 Colberg SR, Sigal RJ, Fernhall B, et al. Exercise and type 2 diabetes: the American College of Sports Medicine and the American Diabetes Association joint position statement. Diabetes Care 2010;33:e147-67. 